\title{
Partner-Assisted Coping Skills Training
}

National Cancer Institute

\section{Source}

National Cancer Institute. Partner-Assisted Coping Skills Training. NCI Thesaurus. Code C116533.

Any program that aims to teach the partner or caregiver of a patient a specific set of skills intended to help relieve the physical, emotional, and/or mental stress experienced by the patient. 